\title{
Events Surrounding the Early Development of Euglena Chloroplasts: Experiments with Streptomycin in Non-dividing Cells*
}

\author{
By JOAN G. BOVARNICK, SUNG-WEN CHANG, J. A. SCHIFF AND \\ S. D. SCHWARTZBACH
}

Department of Biology, Brandeis University, Waltham, Massachusetts 02154 , U.S.A.

(Received I 2 November I973)

\section{SUMMAR Y}

The concentration of streptomycin $(\mathrm{Sm})$ which selectively inhibits light-induced chloroplast development in non-dividing Euglena is the same as that which induces the loss of green-colony forming ability in dividing organisms. This concentration of Sm has no effect on division or viability. Chlorophyll synthesis is insensitive to streptomycin for the first $12 \mathrm{~h}$ of development but is strongly inhibited after this time. Between 72 and $96 \mathrm{~h}$ after the beginning of chloroplast development, Sm-treated organisms contain $10 \%$ of the chlorophyll and $24 \%$ of the carotenoids of algae developing in the absence of the antibiotic. The chlorophyll-to-carotenoid ratio in treated organisms at 72 to $96 \mathrm{~h}$ is 0.9 , the same as is found at $12 \mathrm{~h}$ for organisms developing in the absence of $\mathrm{Sm}$. In the presence of streptomycin, Euglena never develops the ability to fix $\mathrm{CO}_{2}$ photosynthetically, although $\mathrm{CO}_{2}$ fixation after $12 \mathrm{~h}$ of development in the absence of the antibiotic can be readily detected. At $\mathrm{I} 2 \mathrm{~h}$ of chloroplast development the following parameters are at comparable levels in Sm-treated and untreated organisms: the bound forms of chlorophyll, concentration of cytochrome 552, the activities of ribulose diphosphate carboxylase, NADP-triose phosphate dehydrogenase, the enzymes converting ribose-5-phosphate to ribulose diphosphate, and photosystem II activity measured as dye reduction.

\section{INTRODUCTION}

The classical experiments of Provasoli, Hutner \& Schatz (1948) demonstrated that streptomycin could bring about the irreversible loss of plastid forming ability from dividing Euglena gracilis var. bacillaris without impairing viability or division. There is a large literature on the physiology of this phenomenon which has been reviewed recently (Mego, 1968).

Work with bacterial systems has shown that streptomycin inhibits translation on $70 \mathrm{~S}$ ribosomes (Wallace \& Davis, 1973) by specifically binding to the $30 \mathrm{~S}$ ribosomal subunit (Kaji \& Tanaka, I968; Chang \& Flaks, 1972a,b). Since chloroplasts of Euglena contain 68 S ribosomes (Rawson \& Stutz, 1969; Scott, Munns \& Smillie, I970; Avadhni \& Buetow, 1972; Schwartzbach, Freyssinet \& Schiff, 1974) which bind dihydrostreptomycin (Schwartzbach, Freyssinet \& Schiff, 1973) and which have ribosomal proteins similar to those of Escherichia coli (Freyssinet \& Schiff, 1974), the highly selective effect of streptomycin on plastid inheritance is probably due to the interaction between the antibiotic and the chloroplast ribosome. Streptomycin is, therefore, a useful tool in the elucidation of the role of chloroplast protein synthesis during light-induced chloroplast development. This paper defines the conditions under which the same concentrations of streptomycin which cause plastid loss in dividing organisms will inhibit the formation of various light-induced chloroplast constituents during chloroplast development in non-dividing Euglena. A brief description of this work has already appeared (Bovarnick, Chang \& Schiff, I968).

\footnotetext{
* No. 3 of a series.
} 


\section{METHODS}

Euglena gracilis Klebs var. bacillaris Pringsheim was grown aseptically in the dark on Hutner's pH 8.0 medium (Greenblatt \& Schiff, 1959) with shaking at $26^{\circ} \mathrm{C}$ as previously described (Lyman, Epstein \& Schiff, 196I). All manipulations of dark-grown algae were done under a green safelight (Schiff, 1972). Dark-grown resting organisms were obtained as described previously (Stern, Schiff \& Epstein, 1964b) by using the pH 6.8 resting medium (Holowinsky \& Schiff, 1970), since a relatively high $\mathrm{pH}$ was required to facilitate streptomycin entry. Conditions for normal chloroplast development, including illumination, have been described (Stern, Epstein \& Schiff, 1964a). The method of Zeldin \& Schiff ( 1967 ) was used for determining number of organisms. Chlorophyll and carotenoid levels were measured as described by Stern et al. (1964b). Photosynthetic carbon dioxide fixation was assayed as described previously (Diamond \& Schiff, 1970). Viability and green-colony forming ability were determined by dilution and plating on $\mathrm{pH} 3.5$ medium (Schiff, Lyman \& Russell, 1971) since plating on a low pH medium prevented further streptomycin entry. Methods for fluorescence microscopy have been described (Klein, Schiff \& Holowinsky, 1972).

Vials containing sterile powdered streptomycin sulphate equivalent to I $g$ of free base (Pfizer) received $4.2 \mathrm{ml}$ sterile distilled water to prepare a stock solution containing $200 \mathrm{mg}$ streptomycin base $/ \mathrm{ml}$. This solution was added aseptically to cultures of resting organisms to give a final concentration of $0.05 \%$ streptomycin. Cultures were divided after three days on resting medium with one-half of the culture receiving streptomycin and the other half serving as a control. They were immediately placed in the light to allow chloroplast development to take place (Stern et al. 1964b); the time of light exposure is defined as zero time of development.

Protein was determined by the methods of Lowry, Rosebrough, Farr \& Randall (195I), employing Pro-Sol standards and a Gilford spectrophotometer.

Enzyme extracts were prepared by the method of Latzko \& Gibbs (I969) at $4{ }^{\circ} \mathrm{C}$. Organisms were harvested by centrifuging at $1200 \mathrm{~g}$ for $\mathrm{I} 0 \mathrm{~min}$. The pellet was resuspended in sonication buffer, SB (Io mM-tris- $\mathrm{HCl}$, pH 8.0; I mM-EDTA), recentrifuged at $200 \mathrm{~g}$ for $5 \mathrm{~min}$ and resuspended in 10 to $\mathrm{I} 5 \mathrm{ml} \mathrm{SB}$. Sonication was performed in an iced rosette cuvette for $40 \mathrm{~s}$ (a time found to be optimal) in a Branson S-75 sonifier at $20 \mathrm{kHz}$ and $6 \mathrm{~A}$. The sonicate was clarified by centrifugation at $12000 \mathrm{~g}$ for $10 \mathrm{~min}$ and the supernatant fluid was used as the crude extract for the assay of ribulose I,5 diphosphate carboxylase (RUDPCase), ribose-5-phosphate isomerase, ribulose-5-phosphate kinase and NADPdependent triose phosphate dehydrogenase (NADP-TPDase).

RUDPCase was assayed by a modification of the procedure of Weissbach, Horecker \& Hurwitz (1956). The carboxylase activity in the crude extract was stable for several hours at 0 to $4{ }^{\circ} \mathrm{C}$. The assay mixture contained: tris- $\mathrm{HCl}, \mathrm{pH} 8 \cdot 0,50 \mu \mathrm{mol} ; \mathrm{MgCl}_{2}, 10 \mu \mathrm{mol}$; $\mathrm{NaH}^{14} \mathrm{CO}_{3}, 25 \mu \mathrm{mol}(0.4 \mathrm{mCi} / \mathrm{mmol})$; ribulose I, 5 diphosphate, $\mathrm{Na}$ salt, $0.5 \mu \mathrm{mol}$; $0 . \mathrm{I}$ or $0.2 \mathrm{ml}$ crude extract prepared from $\mathrm{I} 50 \mathrm{ml}$ of suspension containing $6 \times 10^{5}$ organisms $/ \mathrm{ml}$; and enough SB to give a total volume of $0.5 \mathrm{ml}$. The mixture was incubated for $\mathrm{I} 5 \mathrm{~min}$ at room temperature and the reaction stopped by the addition of $0.1 \mathrm{ml}$ of $10 \%$ perchloric acid or concentrated formic acid. After centrifugation (if necessary), $0.1 \mathrm{ml}$ of the supernatant (in triplicate) was pipetted onto glass planchets, dried under an infrared lamp and counted in a Nuclear Chicago model PS7 gas-flow counter operating in the proportional range. Substrate-dependent $\mathrm{CO}_{2}$ fixation was linear with time for at least $15 \mathrm{~min}$ and was proportional to enzyme concentration. The product was 3-phosphoglyceric acid, as verified by paper chromatography according to the method of Bassham \& Calvin ( 1957). 
Ribose-5-phosphate isomerase and ribulose-5-phosphate kinase were assayed in an incubation mixture containing in a final volume of $0.7 \mathrm{ml}$ : tris- $\mathrm{HCl}, \mathrm{pH} 8.0,50 \mu \mathrm{mol}$; $\mathrm{MgCl}_{2}, 10 / \mathrm{mol}$; ribose-5-phosphate, $0.5 \mu \mathrm{M} ; \mathrm{NaH}^{14} \mathrm{CO}_{3}, 5 \mu \mathrm{mol}(0.4 \mathrm{mCi} / \mathrm{mmol}) ; \mathrm{ATP}, 0.5$ $\mu \mathrm{mol} ; 0.1$ or $0.2 \mathrm{ml}$ crude extract prepared from $150 \mathrm{ml}$ of suspension containing about $6 \times 10^{5}$ organisms $/ \mathrm{ml}$. Conditions of assay were as described for RUDPCase.

NADP-triose phosphate dehydrogenase was assayed by a modification of the procedure of Latzko \& Gibbs (1969). The assay mixture contained: tris- $\mathrm{HCl}, \mathrm{pH} \mathrm{8.0,} 100 \mu \mathrm{mol}$; ATP, $4 \mu \mathrm{mol}$; NADPH, $0.14 \mu \mathrm{mol}$; freshly-dissolved reduced glutathione, $4.35 \mu \mathrm{mol} ; \mathrm{MgCl}_{2}$, $10 \mu \mathrm{mol}$; phosphoglycerate kinase, 0.12 units; phosphoglyceric acid, $2.0 \mu \mathrm{mol} ; 0.025$ to $0.2 \mathrm{ml}$ crude extract prepared from $50 \mathrm{ml}$ of suspension containing about $6 \times 10^{5}$ organisms/ $\mathrm{ml}$; and enough water to bring the final volume to $\mathrm{I} \cdot 0 \mathrm{ml}$. Activity was measured in a Gilford spectrophotometer as the decrease in absorbance at $340 \mathrm{~nm}$ after the addition of phosphoglyceric acid. The NAD-dependent triose phosphate dehydrogenase was measured by the same procedure with the NADPH replaced by NADH. The NADP-linked dehydrogenase was labile at $0{ }^{\circ} \mathrm{C}$, and the crude extract was therefore assayed immediately for this activity.

For measurement of the Hill reaction, $1500 \mathrm{ml}$ of suspension containing about $6 \times 10^{5}$ organisms/ml, were harvested and washed with Jagendorf's buffer, JB (Jagendorf \& Wildman. 1954) containing $50 \mathrm{~mm}$-phosphate buffer, $\mathrm{pH} 6.9,400 \mathrm{~mm}$-sucrose and $10 \mathrm{~mm}$ $\mathrm{KCl}$. All operations were carried out at o to $4{ }^{\circ} \mathrm{C}$. The organisms were resuspended as a thick slurry, mixed with acid-washed glass beads to form a dry paste, and ground with a mortar and pestle for 3 to $5 \mathrm{~min}$. The paste was taken up in JB and the mixture allowed to stand in order to sediment the glass beads. The supernatant was decanted, centrifuged at $1000 \mathrm{~g}$ for 3 to $5 \mathrm{~min}$, the pellet discarded and the supernatant recentrifuged at $12000 \mathrm{~g}$ for $10 \mathrm{~min}$. The pellet was resuspended in about $\mathrm{I} .5 \mathrm{ml} \mathrm{JB}$, layered onto a 30 to $60^{\circ} \mathrm{o}(\mathrm{w} / \mathrm{w})$ linear sucrose gradient and centrifuged at $86180 \mathrm{~g}$ for $50 \mathrm{~min}$. The upper green layer was removed, mixed with twice its volume of JB, centrifuged for 10 min at $12000 \mathrm{~g}$, and after resuspension in JB was used to assay Hill activity. This purification was necessary to lower the high endogenous dark rate of dye reduction.

The assay mixture contained $0.1 \mathrm{ml}$ extract, $0.0075 \mu \mathrm{mol}$ of dichlorophenolindophenol, and enough JB to bring the final volume to $0.25 \mathrm{ml}$. Absorbance changes at $600 \mathrm{~nm}$ were measured in a Biospekt model 6r. On illumination with saturating red or white light (about 2000 to $4000 \mathrm{ft}$-candle) the absorbance decreased to a steady state value. When the actinic light was turned off, a reoxidation characteristic of Euglena plastid preparations (Olson \& Smillie, 1963; Russell \& Lyman, 1968) was observed. The steady state rate achieved in the light was taken as a measure of the Hill reaction. This activity was inhibited more than $90 \%$ by $10 / \mathrm{M}$-DCMU and heated extracts had no activity.

The bulk forms of chlorophyll described by French \& Elliot (1958) were determined by low temperature derivative spectrophotometry performed with a commercial model of the Norris-Butler spectrophotometer (Butler \& Norris, 1960), the Biospekt model 6I fitted with a derivative output. For these measurements, $10 \mathrm{ml}$ of suspension were centrifuged and the pellet resuspended in $1.0 \mathrm{ml}$ resting medium. About $0.2 \mathrm{ml}$ of this suspension was added to a cuvette, frozen with liquid nitrogen and scanned from 500 to $710 \mathrm{~nm}$, recording both the absorption spectrum and the first derivative of it.

Cytochrome 552 was determined by a modification of the procedures of Perini, Kamen \& Schiff (1964a). Approximately $300 \mathrm{ml}$ of fully green suspension were harvested by centrifugation; larger amounts were used for dark-grown resting organisms or for early stages of development. The pellet was resuspended in acetone and washed with acetone at room temperature until cleared of pigment. The residue was centrifuged and resuspended in fresh 
diethyl ether, transferred to filter paper, and washed thoroughly with ether to remove the remaining acetone. The powder was rapidly air-dried on the filter, scraped into a graduated centrifuge tube which was covered with Parafilm and stored at $4{ }^{\circ} \mathrm{C}$ in a desiccator over $\mathrm{P}_{2} \mathrm{O}_{5}$. The acetone powders were resuspended in about $\mathrm{r} \cdot \mathrm{O} \mathrm{ml}$ of buffer salt solution, BS $\left(0.2 \mathrm{M}-\mathrm{NaH}_{2} \mathrm{PO}_{4}, 0.3 \mathrm{M}-\mathrm{NaCl}, \mathrm{pH} \mathrm{6.5}\right)$, allowed to stand in an ice bath for 30 to $60 \mathrm{~min}$, then centrifuged at $1060 \mathrm{~g}$ for $5 \mathrm{~min}$ at room temperature and the supernatant drawn off. This extraction was repeated several times until no more colour was extracted and the supernatants were combined. This extract was then centrifuged for 45 to $60 \mathrm{~min}$ at $105536 \mathrm{~g}$ at $4{ }^{\circ} \mathrm{C}$. The resulting optically-clear supernatant fluid was scanned in the Cary Model 14 recording spectrophotometer from 500 to $700 \mathrm{~nm}$ using the $0 . \mathrm{I}$ slide wire. Although this method also extracts the cytochrome 556 of the mitochondria, we have found that this is a small but constant contaminant since the concentration of this cytochrome does not change during development (Perini, Schiff \& Kamen, 1964 $b$ ). The absolute amount of cytochrome 552 present at any time during chloroplast development was calculated by subtracting the value obtained at zero time (dark-grown organisms). In practice the extinction at about $580 \mathrm{~nm}$ was subtracted from the extinction at $55^{2} \mathrm{~nm}$ to correct for nonspecific absorption, and the cytochrome 552 concentration was calculated using a nm extinction coefficient of 27 .

\section{RESULTS AND DISCUSSION}

\section{Inhibition of pigment formation by streptomycin}

Fig. I shows the accumulation of chlorophyll in dark-grown resting Euglena exposed to light in the presence of various concentrations of streptomycin. Maximum inhibition of chlorophyll accumulation occurred at concentrations of streptomycin greater than $0.04 \%$. We therefore adopted $0.05 \%$ streptomycin for all subsequent experiments and the full kinetics of greening at this concentration are shown in Fig. 1. During the first $14 \mathrm{~h}$ of development chlorophyll synthesis was insensitive to streptomycin. Streptomycin inhibition was observed only during the period of rapid chlorophyll synthesis from 14 to $72 \mathrm{~h}$. The maximum amount of chlorophyll formed at the end of 72 to $96 \mathrm{~h}$ in the presence of streptomycin was about $10 \%$ of the amount which would be formed in untreated organisms. Addition of streptomycin 5 or $\mathrm{I} 2 \mathrm{~h}$ before illumination yielded the same kinetics of chlorophyll formation as did addition of streptomycin at the time of light exposure, suggesting that the insensitivity of the lag period was probably not caused by the failure of streptomycin to reach its intracellular site of action.

Dark-grown non-dividing organisms which received streptomycin at various times after exposure to light showed an onset of inhibition of chlorophyll formation 15 to $20 \mathrm{~h}$ after streptomycin addition. Fig. 2 shows that the earlier streptomycin was added, the lower the final amount of chlorophyll that was formed.

\section{Carotenoid formation}

When normal dark-grown resting organisms were exposed to light, carotenoid levels did not change significantly during the first 12 to $14 \mathrm{~h}$ of development (Stern et al. $1964 \mathrm{~b}$ ). The initial carotenoid levels were the same in streptomycin treated and untreated organisms up to this time but further carotenoid accumulation was inhibited (Table I). Streptomycin treatment resulted in a final carotenoid level of $24 \%$ of the amount normally found at the end of chloroplast development. The chlorophyll to carotenoid weight ratio in streptomycin treated organisms at $96 \mathrm{~h}$ was 0.9 , a value comparable to that found at 12 to $14 \mathrm{~h}$ for 


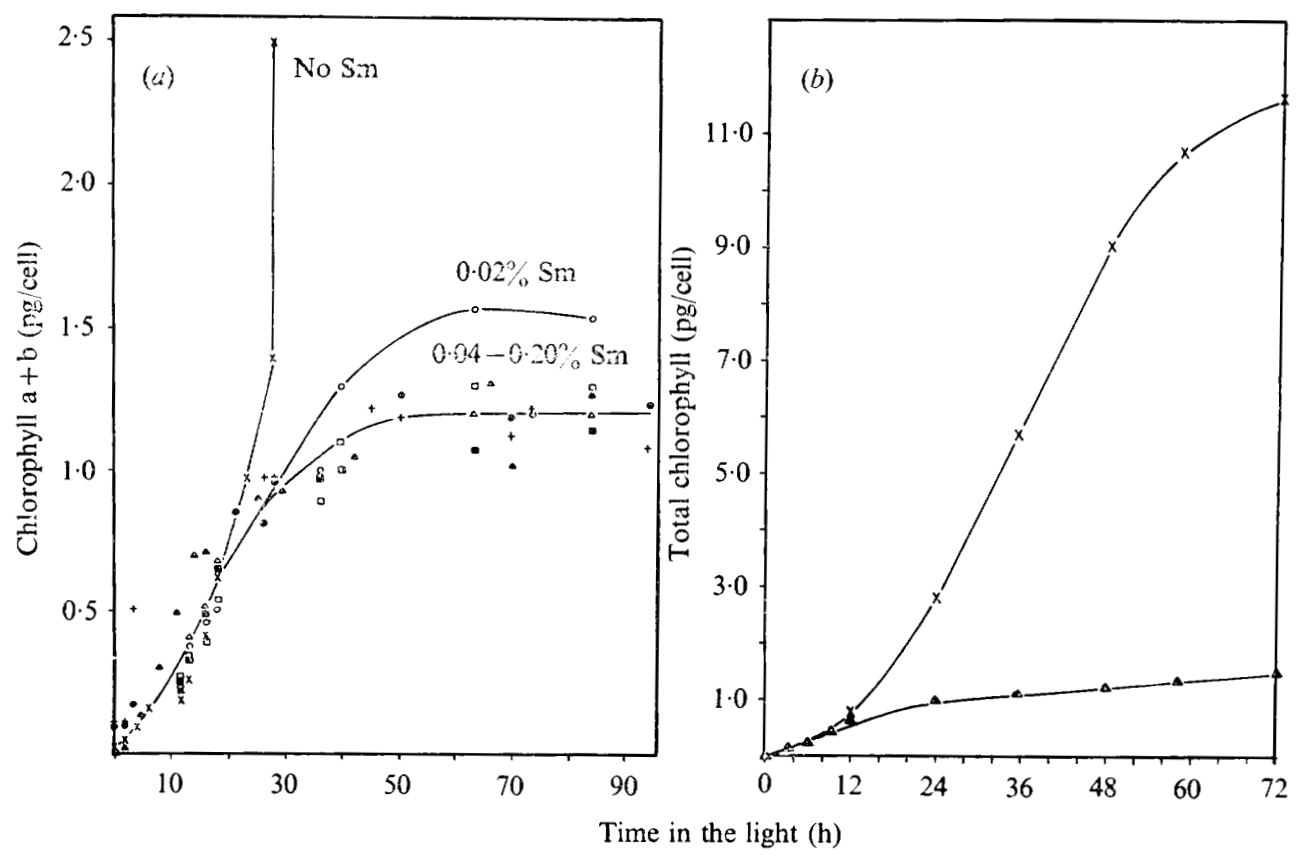

Fig. I. (a) Light-induced chlorophyll formation in dark-grown resting Euglena as a function of streptomycin concentration. (b) Light-induced chlorophyll formation in dark-grown resting Euglena with and without $0.05 \%$ streptomycin. Streptomycin conen $(\%): \times$ no Sm; $0,0.02$; $\square, 0.04 ; \Delta, 0.05 ; \mathbf{m}, 0.06 ; ., 0.08 ; 0,0.10 ;+, 0.20$.

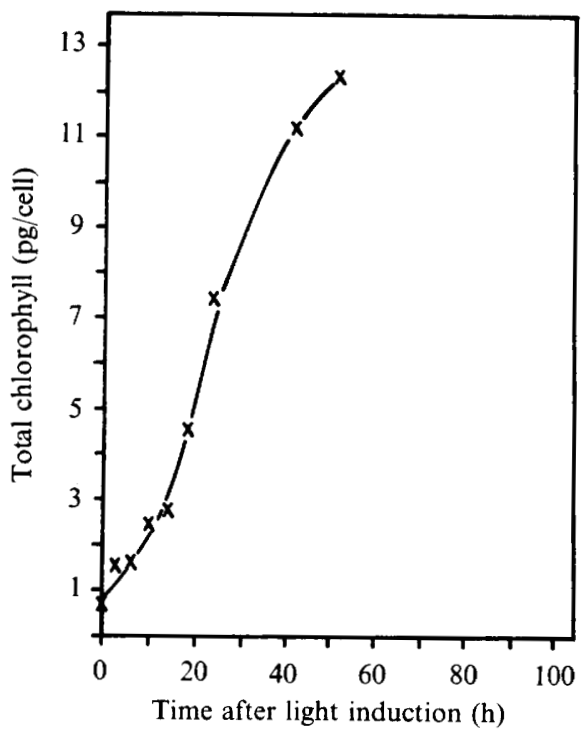

Fig. 2. The effect of the time of addition of streptomycin on the final amount of light-induced chlorophyll accumulation in resting organisms. The amount of chlorophyll when synthesis ceases is plotted as a function of the time after light induction that streptomycin was added. 
Table I. Influence of $(0.05 \%)$ streptomycin on carotenoid accumulation during light-induced chloroplast development in non-dividing Euglena

\begin{tabular}{ccc} 
Time in light $(\mathrm{h})$ & \multicolumn{2}{c}{ Carotenoids (pg/organism) } \\
0 & $0.26 \pm 0.07$ & $+\mathrm{Sm}$ \\
$\mathrm{I}-5$ & $0.25 \pm 0.04$ & - \\
$5.5-7$ & $0.30 \pm 0.08$ & $0.3 \mathrm{I} \pm 0.19$ \\
$8-\mathrm{I} 2$ & $0.39 \pm 0.04$ & - \\
$15-24$ & $0.66 \pm 0.09$ & $0.40 \pm 0.05$ \\
$30-42$ & $1.04 \pm 0.21$ & $0.56 \pm 0.92$ \\
$42-54$ & $1.48 \pm 0.17$ & $0.70 \pm 0.19$ \\
$55-68$ & $1.68 \pm 0.43$ & $0.73 \pm 0.48$ \\
$69-72$ & $2.10 \pm 0.2 \mathrm{I}$ & $0.82 \pm 0.1 \mathrm{I}$ \\
$84-96$ & $2.62 \pm 0.19$ & $0.84 \pm 0.12$
\end{tabular}

The data are the means of several experiments \pm the $95 \%$ confidence intervals of the means.

streptomycin treated and untreated organisms. This value was different from the ratio of about 3 found in untreated Euglena at $96 \mathrm{~h}$ of development. These results suggested that the pattern of streptomycin inhibition of carotenoid synthesis was similar to that found for inhibition of chlorophyll synthesis.

\section{Green-colony forming ability of non-dividing organisms treated with streptomycin}

A culture of dark-grown resting organisms received streptomycin at a concentration of $0.05 \%$. One half was placed in the light and the other half remained in the dark. At various times samples were plated for the determination of the number of organisms capable of forming colonies as well as the number of organisms which had lost the ability to transmit chloroplasts to their progeny. The latter formed white rather than green colonies. Plating efficiencies (number of colonies divided by total number of organisms plated) showed that streptomycin treatment had no effect on viability under resting conditions in the light or the dark, indicating that the streptomycin inhibition of chloroplast development was not caused by a loss of cell viability. Similar results were obtained when dividing organisms were used (Provasoli et al. 1948).

When streptomycin was added at the time of exposure of dark-grown resting organisms to light, there was a rapid loss of green-colony forming ability followed by a slower loss (Fig. 3). After 10 to $\mathrm{I} 2 \mathrm{~h}$ of exposure to streptomycin, $80 \%$ of the organisms had lost the ability to form green colonies. The failure to inhibit chlorophyll synthesis in light-induced resting organisms during this time must represent a true insensitivity of chlorophyll synthesis to the antibiotic and not a failure of the antibiotic to reach its site of action. When streptomycin was added at later times after exposure of the organisms to light, green-colony formation was lost somewhat more slowly and after $18 \mathrm{~h}$ light exposure it required about $20 \mathrm{~h}$ to achieve $80 \%$ loss of green-colony forming ability. Since washing by dilution and plating on streptomycin-free media did not reverse the effect of streptomycin, the antibiotic must be tightly bound at its site of action. If we assume that the loss of green-colony forming ability is a function of the amount of streptomycin per binding site, the light-induced increase in the time necessary for $80 \%$ inactivation of green-colony forming ability could be due to a constant rate of streptomycin entry and a light-induced synthesis of streptomycin binding sites. In bacteria, it has been shown that dihydrostreptomycin binds tightly to $70 \mathrm{~S}$ ribosomes inhibiting protein synthesis (Kaji \& Tanaka, I968; Chang \& Flaks, 1972a, $b$ ) 
Time of addition of Sm after light induction (h)

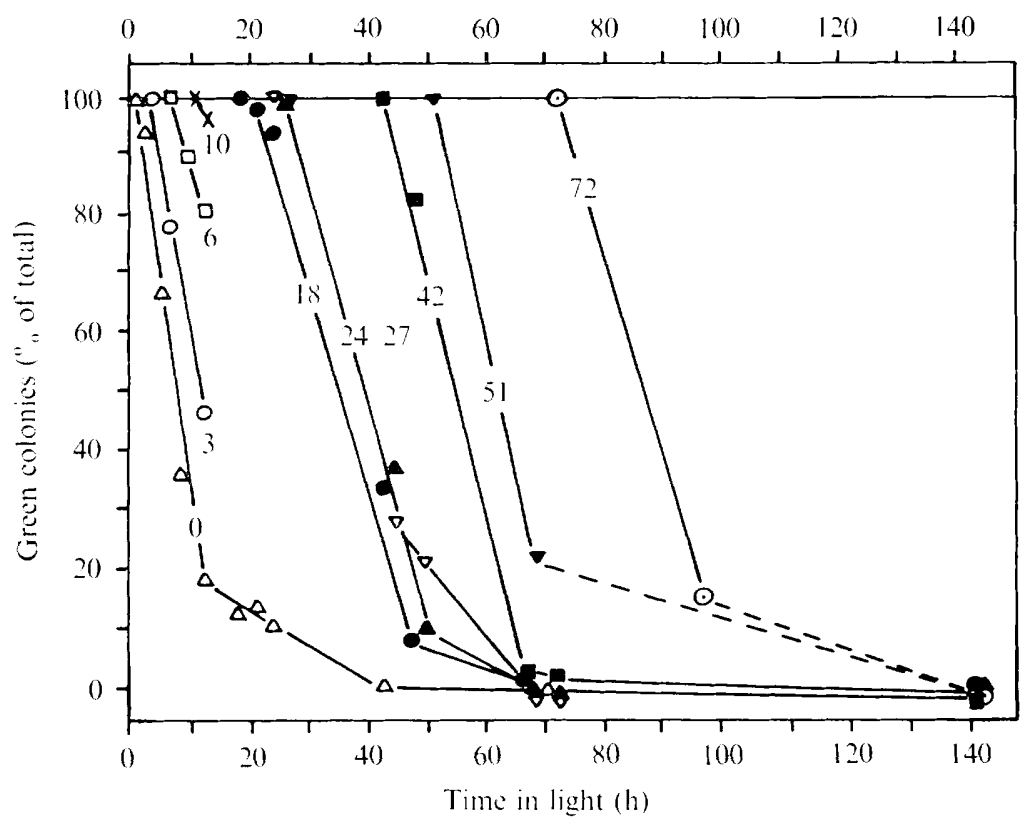

Fig. 3. Green-colony forming ability of organisms developing under resting conditions in the presence of streptomycin. Streptomycin $(0.05 \%)$ was introduced after cultures had been developing for various periods of time in the light (see top of graph and times given on the various curves). At various times thereafter, samples were withdrawn from each of these cultures and the number of green colonies (as a percentage of total white plus green colonies) determined; these values give the curves shown in the Figure. For example, the curve labelled 18 represents a culture of darkgrown resting cells which had been in the light for $18 \mathrm{~h}$ before receiving streptomycin, and the points shown represent portions withdrawn for plating at times ranging from zero to $122 \mathrm{~h}$ thereafter (i.e. 18 and $\mathrm{I} 40 \mathrm{~h}$ after light induction, respectively).

while in Euglena, dihydrostreptomycin preferentially binds to $68 \mathrm{~S}$ chloroplast ribosomes (Schwartzbach et al. 1973). A light-induced synthesis of chloroplast ribosomal RNA has also been demonstrated (Cohen \& Schiff, 1973). The decreased rate of loss of green-colony forming ability with length of light exposure is probably a reflection of an increase in the number of chloroplast ribosomes, and not a consequence of a light-induced permeability change.

\section{Washing experiments to determine the time required for streptomycin permeation}

The interpretation of further experiments using streptomycin as an inhibitor of chloroplast development requires a precise knowledge of the time needed for the inhibitor to enter the algae in an effective concentration. Streptomycin, once taken up, seems to be tightly bound within the cells and might be resistant to removal by extensive washing. Streptomycin $(0.05 \%)$ was added to dark-grown resting organisms and they were immediately exposed to light. At various times thereafter, the organisms were separated by millipore filtration, and recovered from the filter by resuspension in fresh resting medium; development was then allowed to continue for $72 \mathrm{~h}$ in the light. The washing procedure did not inhibit chloroplast development. Fig. 4 shows that the longer the organisms were in contact with streptomycin, the greater was the inhibition of chlorophyll formation after washing. One hour of streptomycin treatment resulted in a negligible inhibition of chlorophyll synthesis. Five to six hours 


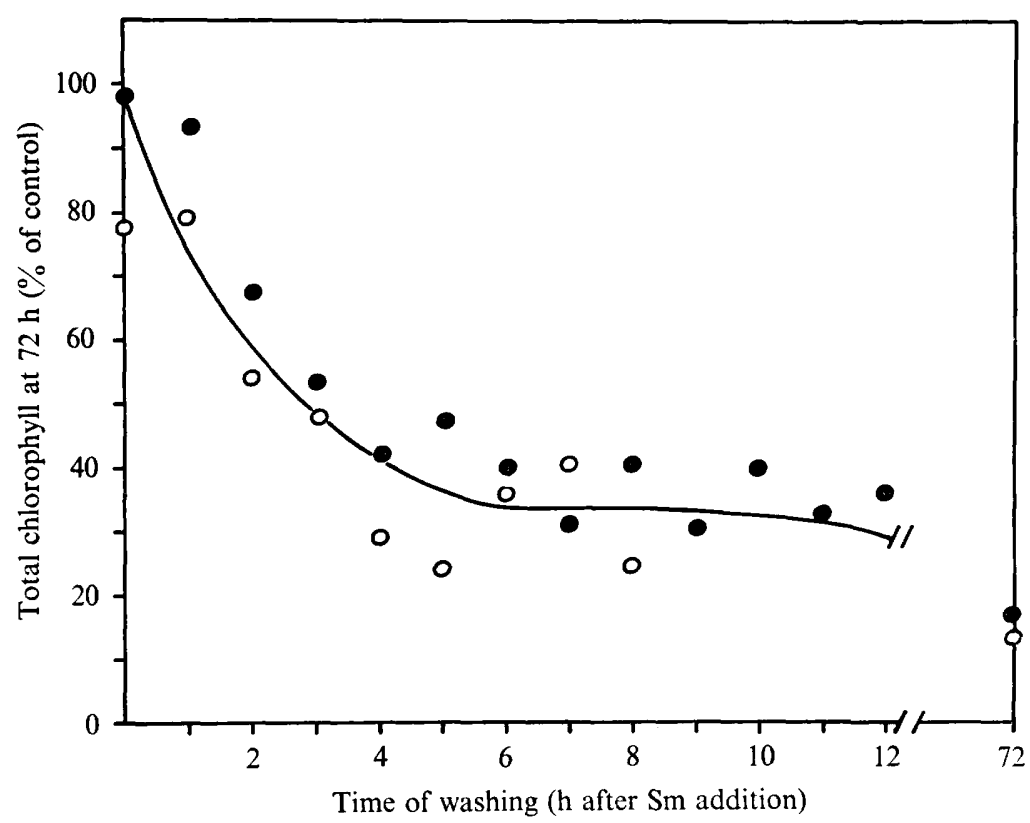

Fig. 4. Streptomycin (0.05\%) was added to a culture of dark-grown resting Euglena and the culture immediately placed in the light. At the times indicated, $10 \mathrm{ml}$ of culture were passed through a sterile $0.45 \mu \mathrm{m}$ Millipore filter and the organisms remaining on the filter washed with about $100 \mathrm{ml}$ sterile resting medium. The organisms were transferred from the filter into $25 \mathrm{ml}$ sterile resting medium and this suspension was returned to the light. After $72 \mathrm{~h}$ from the start of the experiment, the algae were counted, pigments extracted, and chlorophyll determined. The data represent percentages computed from a comparison of the chlorophyll content of each sample with the chlorophyll formed by control organisms at $72 \mathrm{~h}$. Control organisms received no streptomycin and were washed at zero time. The results of two separate experiments are shown $(0$ and $O)$.

of streptomycin treatment resulted in about a $75 \%$ inhibition of chlorophyll synthesis. Organisms which developed for $72 \mathrm{~h}$ in the presence of streptomycin showed an $85 \%$ reduction of chlorophyll synthesis. The kinetics of the loss of the ability to form chlorophyll as a function of time closely resembled the loss of green-colony forming ability (Fig. 3). It appears that the complete permeation of streptomycin requires about 5 to $7 \mathrm{~h}$ when the antibiotic is added at zero time of development.

\section{The development of photosynthetic $\mathrm{CO}_{2}$ fixation in the presence of streptomycin}

Stern et al. (1964b) have described the normal appearance of photosynthetic competence during chloroplast development in Euglena and have shown that net photosynthetic carbon dioxide fixation can be detected by $6 \mathrm{~h}$ development, with net oxygen evolution detectable at about 3 to $4 \mathrm{~h}$ develop ment (Schiff, 1963). As with chlorophyll, photosynthetic capacity as measured by $\mathrm{CO}_{2}$ fixation increased slowly for nearly $\mathrm{i} 2 \mathrm{~h}$, after which the increase became much more rapid. Development ceased after 72 to $96 \mathrm{~h}$ (Stern et al. 1964b). When streptomycin was added to dark-grown resting organisms, there was reduced development of the ability to fix carbon dioxide (Table 2). The photosynthetic efficiency and ability to fix $\mathrm{CO}_{2}$ of algae developing for $\mathrm{I} 2 \mathrm{~h}$ in the presence of streptomycin was significantly lower than in algae not treated with the antibiotic.

Experiments were performed to determine whether streptomycin was truly inhibiting the synthesis of a component of the photosynthetic apparatus or whether it was merely inhibit- 
Table 2. Various photosynthetic parameters in dark-grown resting Euglena exposed to light for $\mathrm{I} 2 \mathrm{~h}$ in the presence and absence of streptomycin

Parameter

Chlorophyll $\mathrm{a}+\mathrm{b}$ (pg/organism)

Carotenoids (pg/organism)

Photosynthetic carbon dioxide fixation

(10 $\times$ pmol fixed/10 min/organism)

Photosynthetic efficiency

( $\mu \mathrm{mol} \mathrm{CO}$ fixed/1o min /mg chlorophyll)

Hill reaction ( $E / \mathrm{s} / \mathrm{mg}$ chlorophyll)

Cytochrome 552 ( $\mathrm{IO}^{5} \times \mathrm{pmol} /$ organism)

Ribulose diphosphate carboxylase ( $\mu \mathrm{mol} \mathrm{CO}_{2}$ fixed/mg protein $/ \mathrm{h}$ )

Ribose-5-phosphate conversion to 3-phosphoglyceric acid

( $\mu \mathrm{mol} \mathrm{CO}_{2}$ fixed $/ \mathrm{mg}$ protein $/ \mathrm{h}$ )

Triose phosphate dehydrogenase

(NADP linked)

( $\mu \mathrm{mol}$ NADPH oxidized $/ \mathrm{mg}$ protein $/ \mathrm{h}$ )
No addition

$0.20 \pm 0.025$

$0.39 \pm 0.04$

$20 \pm 2 \cdot 9$

$10 \pm 2 \cdot 2$

$0.569 \pm 0.07 \mathrm{I}$

$0.16 \pm 0.19$

$0 \cdot 23 \pm 0 \cdot 14$

$0.15 \pm 0.07$

$9 \cdot 9 \pm 2 \cdot 8$
Streptomycin added to final concentration of $0.05 \%$

$0.21 \pm 0.015$

$0.40 \pm 0.05$

$6 \cdot 2 \pm 2 \cdot 2$

$3 \cdot 0 \pm 1 \cdot 0$

$0.518 \pm 0.049$

$0.14 \pm 0.13$

$0.23 \pm 0.08$

$0 \cdot 10 \pm 0.02$

$9 \cdot 2 \pm 1 \cdot 9$

The data are the means of several experiments, \pm the $95 \%$ confidence intervals of the means.

ing $\mathrm{CO}_{2}$ fixation by acting on some component of the already-synthesized machinery. When streptomycin $(0.05 \%)$ was added to organisms which had already developed the ability to fix. $\mathrm{CO}_{2}$, there was no detectable inhibition of $\mathrm{CO}_{2}$ fixation. This did not appear to be caused by slow permeation of streptomycin since $\mathrm{CO}_{2}$ fixation was not affected when fully-green organisms were incubated with streptomycin for 20 and $40 \mathrm{~h}$.

Streptomycin uncouples the synthesis of chlorophyll and the development of the ability to fix $\mathrm{CO}_{2}$ when measured at $2 \mathrm{~h}$ of development (Table 2). While chlorophyll formation for the first $12 \mathrm{~h}$ was unaffected by streptomycin, the amount of photosynthetic $\mathrm{CO}_{2}$ fixation was low. This can be seen from a comparison of the photosynthetic efficiencies, i.e. photosynthesis on a chlorophyll basis (Table 2). During the first $12 \mathrm{~h}$, streptomycin affects the synthesis of some component(s) necessary for the achievement of normal rates of photosynthetic $\mathrm{CO}_{2}$ fixation. In an attempt to learn more about this inhibition, various components of the photosynthetic apparatus were measured in organisms undergoing plastid development for $\mathrm{I} 2 \mathrm{~h}$ in the presence and absence of streptomycin.

\section{Influence of streptomycin on formation of other components of the photosynthetic apparatus}

French \& Elliott (1958), using derivative spectroscopy, showed that normal green Euglena contained three bound forms of chlorophyll: $\mathrm{C}_{675}, \mathrm{C}_{685}$, and $\mathrm{C}_{695}$. Using similar techniques L. Fulco and J. A. Schiff (unpublished) have shown that all three bulk forms of chlorophylls are formed in the period prior to $2 \mathrm{~h}$ of illumination. Fig. 5 demonstrates the presence of all three normal bulk forms of chlorophyll in the streptomycin-treated and untreated organisms after $\mathrm{I} 2 \mathrm{~h}$ of chloroplast development. Identical results have been obtained after $96 \mathrm{~h}$ in the light.

Development of the Hill reaction, as measured with 2,6-dichlorophenol-indophenol, was not affected by streptomycin, indicating that the impairment of carbon dioxide fixation in 


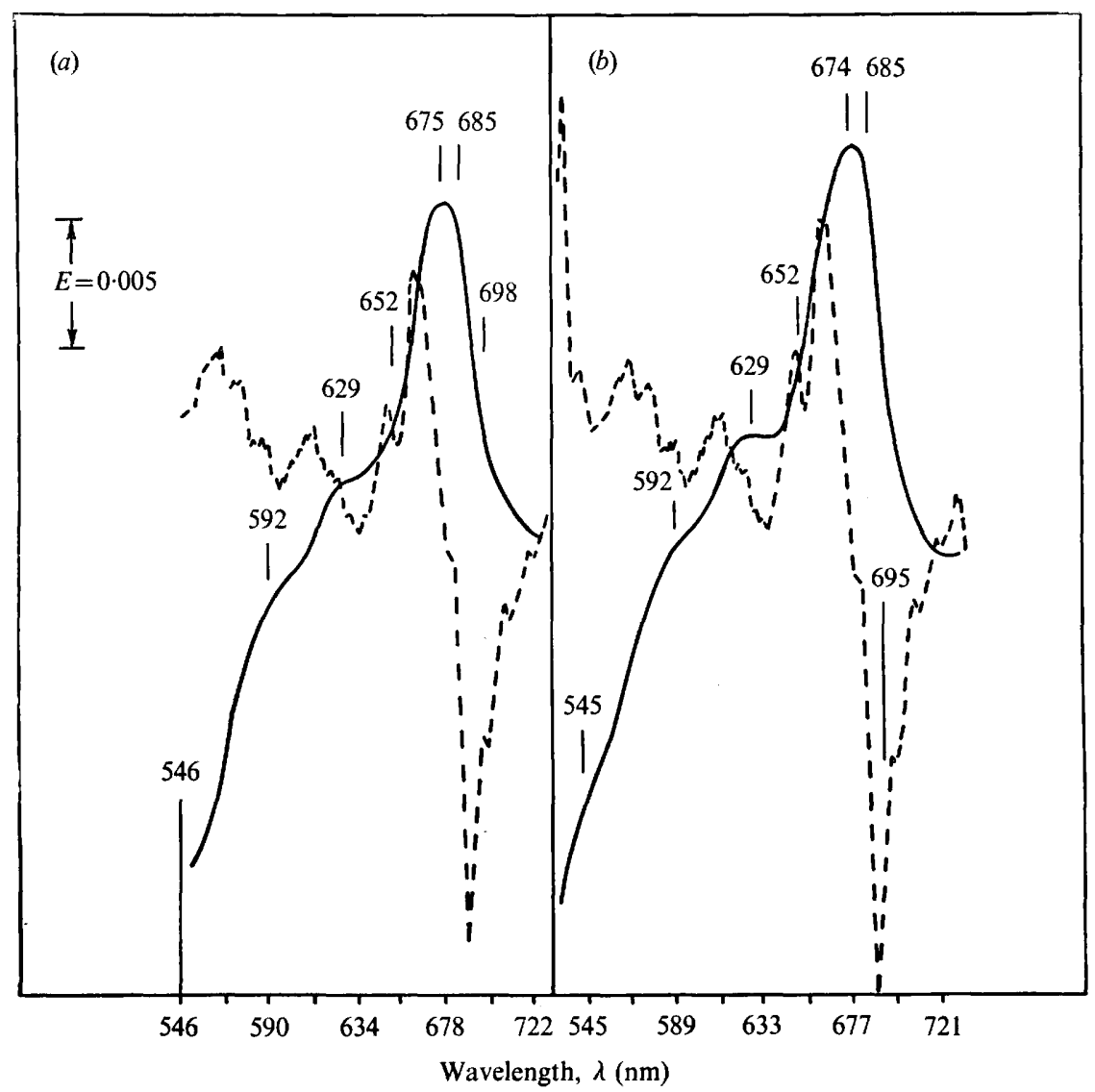

Fig. 5. Low temperature integral and derivative spectra of intact dark-grown resting Euglena after $12 \mathrm{~h}$ in the light in the absence $(a)$ or presence $(b)$ of streptomycin. The organisms were frozen in liquid nitrogen and were measured in a Biospekt Model 61 spectrophotometer. - - Extinction, E; ,$--- \mathrm{d} E / \mathrm{d} \lambda$.

the streptomycin-treated organisms could not be attributed to inhibition of system II of photosynthetic electron transport. Table 2 also shows that the cytochrome 552, ribulose diphosphate carboxylase, the enzymes converting ribose-5-phosphate to ribulose diphosphate, and the NADP-triose phosphate dehydrogenase were all present in the streptomycintreated organisms at $\mathrm{I} 2 \mathrm{~h}$, at levels comparable to those in the controls.

The data in this paper indicate that light-induced chlorophyll synthesis in non-dividing Euglena is insensitive to streptomycin for the first $\mathrm{I} 2 \mathrm{~h}$ of development but is almost completely arrested by streptomycin after this time. This suggests that the first $\mathrm{I} 2 \mathrm{~h}$ of chlorophyll formation do not require protein synthesis on chloroplast ribosomes. Ribulose diphosphate carboxylase activity is already substantial in the dark-grown cells and does not increase appreciably during the first I2 h (Bovarnick, Schiff, Freedman \& Egan, 1974); it is no surprise that the $\mathrm{I} 2 \mathrm{~h}$ level is unaffected by streptomycin. The same situation may apply to cytochrome 552 but ambiguities in the measurement of this component do not permit a clear decision as to whether or not there is synthesis of this component during the first $\mathrm{I} 2 \mathrm{~h}$. The $12 \mathrm{~h}$ level of the NADP-triose phosphate dehydrogenase is unaffected by development in the presence of streptomycin. Thus the syntheses during the first $12 \mathrm{~h}$ of 
development of the photosynthetic apparatus that we have measured are not affected by streptomycin, but some are strongly inhibited thereafter (Bovarnick et al. 1974). This has been confirmed by us with fluorescence microscopy, and by electron microscopy (BenShaul, Silman \& Ophir, 1972) where the structure of the developing plastid after $72 \mathrm{~h}$ in the presence of streptomycin resembles the normal plastid at $\mathrm{I} 2$ to $\mathrm{I} 4 \mathrm{~h}$ development.

An exception to this pattern is the development of the ability to fix $\mathrm{CO}_{2}$. This is more strongly inhibited by streptomycin than is the formation of chlorophyll, and yields lower photosynthetic efficiencies at $\mathrm{r} 2 \mathrm{~h}$. The formation of at least one component of the photosynthetic apparatus not yet identified is inhibited by streptomycin during the first $\mathrm{I} 2 \mathrm{~h}$ of plastid development. The site of this developmental lesion is as yet undetermined.

This investigation was supported by grants from the National Institutes of Health, GM 14595, and by an American Cancer Society institutional grant, IN-29. During the period of this investigation, J.G.B. was a predoctoral fellow of the National Institutes of Health, and S.D.S. a predoctoral trainee. Parts of this work were submitted by J.G.B. and S.-W.C. to Brandeis University in partial fulfillment of the requirements for Ph.D. and M.A. degrees respectively.

\section{REFERENCES}

Avadhani, N. G. \& Buetow, D. E. (I972). Isolation of active polyribosomes from the cytoplasm, mitochondria and chloroplasts of Euglena gracilis. Biochemical Journal 128, 353-365.

Bassham, J. A. \& Calvin, M. (1957). In The Path of Carbon in Photosynthesis. Englewood Cliffs, New Jersey: Prentice-Hall.

Ben-Shaul, Y., Silman, R. \& OphiR, I. (1972). Effects of streptomycin on the ultrastructure of plastids in Euglena. Physiologie Vegetale Io, 255-268.

Bovarnick, J. G., Chang, S. W. \& Schiff, J. A. (1968). Streptomycin (Sm) inhibition of the development of photosynthetic competence in illuminated dark grown non-dividing cells of Euglena. Plant Physiology 43, S6.

Bovarnick, J. G., Schiff, J. A., Freedman, Z. \& Egan, J. M., Jun. (1974). Events surrounding the early development of Euglena chloroplasts: cellular origins of chloroplast enzymes in Euglena. Journal of General Microbiology 83, 63-71.

Butler, W. L. \& NorRis, K. H. (1960). Spectrophotometry of dense light scattering materials. Archives of Biochemistry and Biophysics 87, $3 \mathrm{I}-40$.

Chang, F. N. \& Flaks, J. G. (1972a). Binding of dihydrostreptomycin to Escherichia coli ribosomes: characteristics and equilibrium of the reaction. Antimicrobial Agents and Chemotherapy 2, 294-307.

Chang, F. N. \& Flaks, J. G. (1972b). Binding of dihydrostreptomycin to Escherichia coli ribosomes: kinetics of the reaction. Antimicrobial Agents and Chemotherapy 2, 308-319.

CoHen, D. \& SCHIfF, J. A. (1973). Photoregulation of formation and turnover of chloroplast rRNA (ChlrRNA) and cytoplasmic r RNA (CytrRNA) during chloroplast development in Euglena gracilis Klebs var. bacillaris Pringsheim. Biophysical Journal 133, I I a.

Diamond, J. \& Schiff, J. A. (I970). Insensitivity of development of photosynthetic competence to doses of ultraviolet light which block green colony formation in Euglena. Canadian Journal of Botany 48, 12771283.

French, C. \& Elliot, R. F. (I958). The absorption spectra of chlorophylls in various algae. Carnegie Institute of Washington Yearbook 57, 278-286.

Freyssinet, G. \& SChiff, J. A. (1974). The chloroplast and cytoplasmic ribosomes of Euglena. II. Characterization of ribosomal proteins. Plant Physiology 53, 543-554.

Greenilatt, C. L. \& Schiff, J. A. (1959). A pheophytin-like pigment in dark adapted Euglena gracilis. Journal of Protozoology 6, 23-28.

Holowinsky, A. W. \& SChiff, J. A. (1970). Events surrounding the early development of Euglena chloroplasts. I. Induction by preillumination. Plant Physiology 45, 339-347.

JAGENDORF, A. \& WiLdman, S. G. (1954). The proteins of green leaves. VI. Centrifugal fractionation of tobacco leaf homogenates and some properties of isolated chloroplasts. Plant Physiology 29, 270-279. 
KAJI, H. \& TANAKA, Y. (I968). Binding of dihydrostreptomycin to ribosomal subunits. Journal of Molecular Biology 32, 221-230.

Klein, S., SCHIFF, J. A. \& Holowinsky, A. W. (1972). Events surrounding the early development of Euglena chloroplasts. II. Normal development of fine structure and the consequences of preillumination. Developmental Biology 28, 253-273.

Latzko, E. \& GibBs, M. (1969). Enzyme activities of the carbon reduction cycle in some photosynthetic organisms. Plant Physiology 44, 295-300.

Lowry, O. H., Rosebrough, J. J., Farr, A. L. \& Randall, R. J. (195I). Protein measurements with the Folin phenol reagent. Journal of Biological Chemistry 193, 265-275.

Lyman, H., Epstein, H. I. \& SChifF, J. A. (196I). Studies of chloroplast development in Euglena. I. Inactivation of green colony formation by u.v. light. Biochimica et biophysica acta 50, 30I-309.

MeGo, J. L. (1968). Inhibitors of the chloroplast system in Euglena. In The Biology of Euglena, vol. 2. Edited by D. Buetow. New York: Academic Press.

Olson, J. M. \& Smillie, R. M. (1963). Light driven cytochrome reactions in Anacystis and Euglena. In Photosynthetic Mechanisms of Green Plants, pp. 56-65. National Science Research Council Publication No. II 45 .

Perini, F., Kamen, M. D. \& Schiff, J. A. (I964a). Iron-containing protein in Euglena. I. Detection and characterization. Biochimica et biophysica acta 88, 74-90.

Perini, F., SChiff, J. A. \& Kamen, M. D. (1964b). Iron-containing protein in Euglena. II. Functional localization. Biochimica et biophysica acta 88, 91-98.

Provasoli, L. S., Hutner, H. \& Schatz, A. (1948). Streptomycin induced chlorophyll-less races of Euglena. Proceedings of the Society for Experimental Biology and Medicine 69, 279-282.

Rawson, J. R. \& STUTz, E. (1969). Isolation and characterization of Euglena gracilis cytoplasmic and chloroplast ribosomes and their ribosomal RNA components. Biochimica et biophysica acta 19o, 368380 .

Russell, G. K. \& Lyman, H. (1968). Isolation of mutants of Euglena gracilis with impaired photosynthesis. Plant Physiology 43, I284-I290.

SCHiff, J. A. (1963). Oxygen exchange by Euglena cells undergoing chloroplast development. Carnegie Institute of Washington Yearbook 62, 375-378.

SCHIF, J. A. (1972). A green safelight for the study of chloroplast development and other photomorphogenetic phenomena. In Methods in Enzymology, vol. 24, pp. 32 I-322. Edited by A. San Pietro. New York and London: Academic Press.

SChiff, J. A., Lyman, H. \& Russell, G. K. (197I). Isolation of mutants from Euglena gracilis. In Methods in Enzymology, volume 23, pp. I43-162. Edited by A. San Pietro. New York and London: Academic Press.

Schwartzbach, S. D., Freyssinet, G. \& Schiff, J. A. (1973). Binding of dihydrostreptomycin to Euglena VI. chloroplast ribosomes prepared by an improved procedure. Plant Physiology 5I, S 27.

Schwartzbach, S. D., Freyssinet, G. \& SChifF, J. A. (I974). The chloroplast and cytoplasmic ribosomes of Euglena. I. Stability of chloroplast ribosomes prepared by an improved procedure. Plant Physiology 53, 533-542.

Scott, N. S., Munns, R. \& Smillie, R. M. (1970). Chloroplast and cytoplasmic ribosomes in Euglena gracilis. FEBS Letters 10, I49-I 52.

Stern, A. I., Epstein, H. T. \& SChiff, J. A. (1964a). Studies of chloroplast development in Euglena. VI. Light intensity as a controlling factor in development. Plant Physiology 39, 226-23I.

Stern, A. I., Schiff, J. A. \& Epstein, H. T. (1964b). Studies of chloroplast development in Euglena. V. Pigment biosynthesis, photosynthetic oxygen evolution and carbon dioxide fixation during chloroplast development. Plant Physiology 39, 220-226.

Wallace, B. J. \& Davis, B. D. (1973). Cyclic blockade of initiation sites by streptomycin-damaged ribosomes in Escherichia coli: an explanation for dominance of sensitivity. Journal of Molecular Biology 75, 377-390.

Weissbach, A. B., Horecker, J. \& Hurwitz, J. (I956). The enzymatic formation of phosphoglyceric acid from ribulose diphosphate and carbon dioxide. Journal of Biological Chemistry 218, 795-810.

ZELDIN, M. H. \& SCHIFF, J. A. (1967). RNA"metabolism during light-induced chloroplast development in Euglena. Plant Physiology 42, 922-932. 